\title{
Quantitative Trait Loci for Grain Yield in Pearl Millet under Variable Postflowering Moisture Conditions
}

\author{
F. R. Bidinger, T. Nepolean,^ C. T. Hash, R. S. Yadav, and C. J. Howarth
}

\section{ABSTRACT}

Pearl millet marker-assisted selection (MAS) programs targeting adaptation to variable postflowering moisture environments would benefit from quantitative trait loci (QTLs) that improve grain yield across the full range of postflowering moisture conditions, rather than just in drought-stressed environments. This research was undertaken to identify such QTLs from an extensive (12-environment) phenotyping data set that included both stressed and unstressed postflowering environments. Genetic materials were test crosses of $79 \mathrm{~F}_{2}$-derived $\mathrm{F}_{4}$ progenies from a mapping population based on a widely adapted maintainer line (ICMB 841) $\times$ a postflowering drought-tolerant maintainer (863B). Three QTLs (on linkage group [LG] 2, LG 3, and LG 4) were identified as primary candidates for MAS for improved grain yield across variable postflowering moisture environments. The QTLs on LG 2 and LG 3 (the most promising) explained a useful proportion (13-25\%) of phenotypic variance for grain yield across environments. They also co-mapped with QTLs for harvest index across environments, and with QTLs for both grain number and individual grain mass under severe terminal stress. Neither had a significant QTL $\times$ environment interaction, indicating that their predicted effects should occur across a broad range of available moisture environments. We have estimated the benefits in grain yield and accompanying changes in yield components and partitioning indices that would be expected as a result of incorporating these QTLs into other genetic backgrounds by MAS.
F.R. Bidinger, T. Nepolean, and C.T. Hash, International Crops Research Inst. for the Semi-Arid Tropics (ICRISAT), Patancheru P.O., Andhra Pradesh 502 324, India; and R.S. Yadav and C.J. Howarth, Inst. of Grassland and Environmental Research, Aberystwyth, SY23 3EB, UK. Received 15 July 2006. *Corresponding author (t.nepolean@cgiar.org).

Abbreviations: BLUP, best linear unbiased predictor; GRMA, individual grain mass; GRNO, grain number; GRYLD, grain yield; HI, harvest index; LG, linkage group; LOD, logarithm of odds; MAS, marker-assisted selection; PNHI, panicle harvest index; QTL, quantitative trait locus; RFLP, restriction fragment length polymorphism; SSR, simple sequence repeat.

$\mathrm{D}$ ROUGHT STRESS AT various periods during the growing season is a common occurrence in pearl millet [Pennisetum glaucum (L.) R. Br.] (van Oosterom et al., 1996c; Eldin, 1993), and thus is one of the major factors influencing crop yield and yield stability (van Oosterom et al., 1996a, 1996b). Despite this, few millet-breeding programs practice specific selection for either general adaptation to moisture-limited environments or for drought tolerance per se, because of the practical difficulties of doing both. Yieldbased empirical selection for adaptation under naturally occurring stress environments is highly problematic (Blum 1988) because of the unpredictability of naturally occurring stress, the quantitative nature of adaptation, and the consequent predominance of genotype $\times$ environment interaction variance in selection results, as well as the impracticality of sampling a representative range of naturally occurring stress patterns. Yield-based empirical selection for adaptation is possible using managed stress environments (e.g.,

Published in Crop Sci. 47:969-980 (2007)

doi: $10.2135 /$ cropsci2006.07.0465

(C) Crop Science Society of America

677 S. Segoe Rd., Madison, WI 53711 USA

All rights reserved. No part of this periodical may be reproduced or transmitted in any form or by any means, electronic or mechanical, including photocopying, recording, or any information storage and retrieval system, without permission in writing from the publisher. Permission for printing and for reprinting the material contained herein has been obtained by the publisher. 
Bidinger et al., 1987a), but requires considerable resources and is limited to a few types of stress.

Selection for drought tolerance per se is limited by the lack of proven selection criteria. Screening techniques have been proposed for various traits thought to be related to drought tolerance in pearl millet (Yadav and WeltzienRattunde, 1999), but few attempts to actively select for tolerance have been reported. Research on genotype yield differences under terminal (unrelieved postflowering) stress has suggested possible criteria for identifying tolerance to this type of stress (Bidinger et al., 1987b; Fussell et al., 1991). An extensive evaluation of one such criterionmaintenance of panicle harvest index under stress-for improved tolerance of terminal stress indicated that yield gains of $5 \%$ per initial cycle(s) under terminal stress are possible with this criterion (Bidinger et al., 2000). The feasibility of using more basic physiological parameters as selection criteria is limited in pearl millet by the available information on such traits as selection criteria.

Our own recent efforts to improve drought tolerance in pearl millet have focused on the identification of quantitative trait loci (QTLs) for grain yield or closely related traits under terminal stress conditions (Yadav et al., 2002, 2004). Several QTLs have been identified and the process of evaluating their effectiveness is underway (Bidinger et al., 2005; Serraj et al., 2005). The focus on drought tolerance in this work is linked to the relative ease in pearl millet of marker-assisted backcross (MABC) transfer of specific QTLs to improve specific aspects of widely used hybrid parental lines (Bidinger and Hash, 2004). Using $\mathrm{MABC}$ to enhance the drought tolerance of proven parental lines allows the breeder to concentrate on this trait, with the knowledge that the recurrent parents are otherwise fully acceptable to the seed industry (Witcombe and Hash, 2000). This should be an effective, short-term approach, provided the drought tolerance QTLs have sufficient expression in the hybrids of the recipient parental lines to justify the expense, with no negative effects on other desirable traits.

Apart from this specific application, the general breeding requirement remains not simply drought tolerance, but improved adaptation (as measured by grain yield) to the full range of expected moisture conditions during grain filling. Quantitative trait loci that enhance traits specifically linked to grain yield across the full range of grain-filling moisture environments would be more useful to a general breeding program, as they could be deliberately retained in segregating generations by marker-assisted selection (MAS), while phenotypic selection was practiced under stress-free conditions for desired agronomic characteristics. This approach would thus enhance broad adaptation to the full range of grain-filling moisture environments, simultaneously with selection for overall worth. As in the case of MABC for drought tolerance, however, the feasi- bility of this application of MAS depends on the identification of QTLs for yield or for strongly linked traits that are effective across the full range of expected moisture conditions during grain filling.

The objectives of this study were (i) to identify QTLs with favorable effects on grain yield or on closely linked traits that would be effective across a broad range of grainfilling moisture environments, and (ii) to estimate the probable effects of these when used as additional selection criteria (using MAS) during the segregating generations of a conventional millet breeding program.

\section{MATERIALS AND METHODS Plant Materials}

This study was based on 79 skeleton-mapped $\mathrm{F}_{2}$-derived $\mathrm{F}_{4}$ progenies from the mapping population bred from the cross of single inbred plants selected from each of two adapted maintainer lines, ICMB $841 \times 863 \mathrm{~B}$, which was used in an earlier study by Yadav et al. (2004). These were test crossed to the drought-susceptible restorer line PPMI 301 for field phenotyping. Line ICMB 841 (Singh et al., 1990) is of North Indian origin and the parent of several commercial hybrids released for this area. It is regarded as widely adapted and productive but its hybrids do not fill grain well under terminal drought stress. Line $863 \mathrm{~B}$ was bred from the West African Iniadi landrace material (Andrews and Anand Kumar, 1996), which has demonstrated excellent tolerance to terminal drought stress under managed drought-stress conditions at ICRISAT.

\section{Genotyping}

The genotyping of the $\mathrm{F}_{2}$ plants from the ICMB $841 \times 863 \mathrm{~B}$ mapping population and the construction of the linkage map was done and described by Yadav et al. (2004). In this study, collinear markers were removed from the analysis before the map was constructed using Mapmaker/Exp 3.0 (Lander et al., 1987). The map obtained spans a total length of $551 \mathrm{cM}$ and comprises 79 loci including 50 restriction fragment length polymorphism (RFLP) loci (Liu et al., 1994) and 29 simple sequence repeat (SSR) markers (Allouis et al., 2001; Qi et al., 2001, 2004) distributed across the seven linkage groups (LGs) as named by Liu et al. (1994). Minor changes in the positions of closely linked markers $(\sim 1.0 \mathrm{cM})$ were obtained but otherwise all markers mapped to the same positions as the previously published map of this cross.

\section{Phenotyping}

Test-crossed $\mathrm{F}_{4}$ progenies were evaluated in similarly managed replicated trials in the dry-season drought nursery at ICRISAT, Patancheru, India, during the years 1998, 1999, 2000, and 2001. Phenotyping environments each year included a fully irrigated, stress-free environment and two (early- and late-onset) postflowering stress environments. Irrigation in the early-onset treatment was terminated approximately $1 \mathrm{wk}$ before flowering of the main shoot, to initiate the stress about mid-flowering to affect both seed number and seed filling. Irrigation in the late-onset treatment was terminated 7 to $10 \mathrm{~d}$ later to initiate the stress in early to mid-grain filling to affect primarily seed filling. 
All trials were planted in alpha (incomplete block) designs with nine plots per block, replicated thrice. Individual plots were two rows by $4.0 \mathrm{~m}$ long by $0.6 \mathrm{~m}$ apart; net (harvested) plot area was two rows by 3.0 by $0.6 \mathrm{~m}$. Trials were uniformly managed to maximize growth and grain yield within the limits of the moisture treatments, as described in Yadav et al. (2004). Data were recorded on a harvested-area basis for oven-dry biomass and grain yields (GRYLD) and converted to a squaremeter basis. Individual grain mass (GRMA) was determined from the weight of triplicate samples of 100 oven dry grains, and grain number per square meter (GRNO) was estimated from grain yield and individual grain mass. Harvest index (HI) was calculated as the ratio of grain to biomass yield, and panicle harvest index (PNHI) from the ratio of grain to total panicle weights. The former was considered an index of the ability to convert biomass to grain across moisture environments and the latter as a measure of the ability to set and fill grains across moisture environments (Bidinger, 2002).

Results of the 1998 and 1999 evaluations done in the terminal stress treatments only (four of the total of 12 phenotyping environments reported here) were used by Yadav et al. (2004) to assess the effects of year, stress intensity, and tester on identification of QTLs for terminal drought tolerance. This study used data from the full set of phenotyping environments - $4 \mathrm{yr}$ and three postflowering moisture environments - to identify and assess QTLs for grain yield, its two major components (GRNO and GRMA), and the two indices of partitioning efficiency (HI and PNHI), across the full range of postflowering moisture environments.

\section{Data Analysis}

Plot-level data on each trait were subjected to a linear mixed model analysis using ReML in GENSTAT (GENSTAT 6 Committee, 2002). The data across the 12 environments were analyzed based on the following linear mixed effects model:

$$
y_{i j k l}=\mu+E_{i}+R_{i l}+B_{i j l}+G_{k}+(G E)_{k i}+\varepsilon_{i j k l}
$$

where $y_{i j k l}$ is the observation on the $i j k l$ th plot corresponding to progeny $k$ in block $j$ of replicate $l$ in environment $i, \mu$ is the general mean, $E_{i}$ is the effect of environment $i, R_{i l}$ is the effect of replicate $l$ in environment $i, B_{i j l}$ is the effect of block $j$ in replicate $l$ of environment $i, G_{k}$ is the effect of progeny $k,(G E)_{k i}$ is the interaction of progeny $k$ with environment $i$, and $\varepsilon_{i j k l}$ represents the residual for the ijklth plot. Each effect in Eq. [1], except for $\mu$ and $E_{i}$, was treated as a normally distributed random variable with an expected value of zero and a constant variance. Since our major interest here was to assess the consistency of detected QTLs across the three moisture environments, the environment term $E_{i}$ in Eq. [1] was factorially partitioned as $E_{i}=E_{u v}=Y_{u}+$ $M_{v}+(Y M)_{u v}$, with Eq. [1] accordingly expanded to extract the progeny $\times$ moisture-environment interaction effects $(G M)_{k v}$. Here $Y_{u}$ is the effect of year $u, M_{v}$ is the effect of moisture environment $v$, and $(Y M)_{u v}$ represents their interaction, with moisture-environment effects considered fixed. Plot-level data from each of the 12 individual environments were analyzed using the following linear mixed effects model

$$
y_{j k l}=\mu+R_{l}+B_{j l}+G_{k}+\varepsilon_{j k l}
$$

where the replicate effect $R_{l}$, due to its small sample size of three, was treated as fixed. The residual diagnostic plots from ReML analysis of both models indicated that the model assumptions of normality and constant variance were reasonably well satisfied for all five traits.

Multi-environment QTL mapping was done using the best linear unbiased predictors (BLUPs) corresponding to the progeny term $G_{k}$ as obtained from Eq. [1-2], following the method of composite interval mapping as outlined in Utz et al. (2000) and implemented in PLABQTL (Utz and Melchinger, 1996). The presence of a putative QTL in any interval was tested using a logarithm of odds (LOD) threshold of 2.5.

\section{RESULTS AND DISCUSSION Moisture Environments Effects}

The effect of moisture environment was highly significant for all measured variables, as expected in a managed stress environment (Table 1). Grain yields declined from an average of $378 \mathrm{~g} \mathrm{~m}^{-2}$ under favorable conditions during grain filling to $254 \mathrm{~g} \mathrm{~m}^{-2}$ in the moderate, late-onset stress

Table 1. Magnitude and significance of different sources of variation from the mixed model ReML analysis. Moisture environment (treated as a fixed effect) data are Wald statistics. The remaining data are estimates of variance components (with their

\begin{tabular}{|c|c|c|c|c|c|c|}
\hline Source of variation & df & Grain yield & Grain number & Individual grain mass & Harvest index & Panicle harvest index \\
\hline & & $\mathrm{g} \mathrm{m}^{-2}$ & no. $m^{-2}$ & $\mathrm{mg}$ & $\longrightarrow$ & $-\% \longrightarrow$ \\
\hline Year $(Y)$ & 3 & 915 (935) & 22576872 (20167 454) & $1.358(1.792)$ & $0(0.9)$ & $4.16(5.09)$ \\
\hline Moisture environment (M) & 2 & $70.4^{\star \star \star}$ & $24.6^{\star \star \star}$ & $54.9^{\star \star \star}$ & $65.0^{* \star *}$ & $39.7^{\star \star *}$ \\
\hline$Y \times M$ & 6 & $611(357)$ & 5506429 (3254345) & $2.241(1.308)$ & $2.3(1.35)$ & $5.5(3.22)$ \\
\hline Replication within $\mathrm{Y} \times \mathrm{M}$ & 24 & $33(25)$ & 471276 (350570) & $0.003(0.018)$ & $0.4(0.27)$ & $0.12(0.13)$ \\
\hline Blocks within replications & 612 & $169(30)^{\star \star \star}$ & $1958537(424729)^{\star \star \star}$ & $0.242(0.064)^{\star \star \star}$ & $1.25(0.23)^{\star \star \star}$ & $1.17(0.25)^{\star \star \star}$ \\
\hline Progeny (P) & 78 & $92(27)^{\star \star \star}$ & $2080487(558443)^{\star \star \star}$ & $1.312(0.268)^{\star \star \star}$ & $3.42(0.7)^{\star \star \star}$ & $2.8(0.62)^{\star \star \star}$ \\
\hline$P \times Y$ & 234 & $30(25)$ & $1466813(495932)^{\star \star}$ & $0.735(0.133)^{\star \star \star}$ & $1.16(0.25)^{\star \star \star}$ & $0.92(0.3)^{\star \star}$ \\
\hline$P \times M$ & 156 & $20(22)$ & 165631 (343878) & $0(0.062)$ & $0.76(0.22)^{\star \star \star}$ & $0.9(0.29)^{\star \star \star}$ \\
\hline$P \times Y \times M$ & 468 & $34(44)$ & 322985 (727 140) & $0.334(0.135)^{\star}$ & $0(0.32)$ & $0.47(0.432)$ \\
\hline Residual & 1259 & $29.3^{* \star *}$ & $29.5^{\star \star \star}$ & $29.4^{\star \star \star}$ & $29.5^{\star \star \star}$ & $29.7^{\star \star \star}$ \\
\hline
\end{tabular}
SEs shown in parentheses) for the corresponding sources of variation (treated as random effects).

*Significant at $P<0.05$.

${ }^{\star *}$ Significant at $P<0.01$.

${ }^{* * \star}$ Significant at $P<0.001$. 
to $170 \mathrm{~g} \mathrm{~m}^{-2}$ in the severe, early-onset stress (Table 2). Moisture-environment effects on GRYLD were mirrored by similar effects on all yield-related variables, but the absolute reductions varied with trait. Both GRNO and GRMA were more severely reduced in the early-onset stress than they were in the late-onset stress, but the reductions in GRMA were greater in both treatments (38 and $23 \%$ ) than were the reductions in GRNO (29 and 14\%, Table 2), as stress was more severe in both treatments during the determination of GRMA than during the determination of GRNO. Reductions in both HI and PNHI were similar in the late-onset stress $(10 \%)$, but greater in HI (28\%) than in PNHI (20\%) in the early-onset stress (Table 2). This reflects the greater effect of the early-onset stress on productive tiller number, as $\mathrm{HI}$ is reduced by the failure of later tillers to produce grain, which are included in total biomass but make no contribution to grain yield, where PNHI is based only on productive tillers.

None of the effects of the other components of environment in the analysis were significant, apart from block effects (Table 1). The climate of the peninsular Indian dry

Table 2. Ranges and standard errors of difference (SED) of testcrossed $\mathrm{F}_{4}$ progeny best linear unbiased predictors for grain yield and its key components in different moisture environments.

\begin{tabular}{|c|c|c|c|c|}
\hline \multirow[b]{2}{*}{ Trait } & \multicolumn{4}{|c|}{ Best linear unbiased predictors } \\
\hline & $\begin{array}{l}\text { Favorable } \\
\text { conditions }\end{array}$ & $\begin{array}{c}\text { Moderate, } \\
\text { late-onset } \\
\text { stress }\end{array}$ & $\begin{array}{l}\text { Severe, } \\
\text { early-onset } \\
\text { stress }\end{array}$ & $\begin{array}{c}\text { Across } \\
\text { moisture } \\
\text { environments }\end{array}$ \\
\hline \multicolumn{5}{|l|}{ Grain yield $\left(\mathrm{g} \mathrm{m}^{-2}\right)$} \\
\hline Mean & 378 & 254 & 170 & 267 \\
\hline Minimum & 359 & 230 & 150 & 248 \\
\hline Maximum & 401 & 272 & 191 & 286 \\
\hline SED (progeny) & 11.3 & 11.1 & 9.89 & 8.3 \\
\hline \multicolumn{5}{|c|}{ Grain number ( no. × $10^{3} \mathrm{~m}^{-2}$ ) } \\
\hline Mean & 41.2 & 35.3 & 29.4 & 35.3 \\
\hline Minimum & 37.2 & 31.3 & 25.7 & 31.4 \\
\hline Maximum & 44.5 & 38.5 & 32.2 & 38.4 \\
\hline SED (progeny) & 1.61 & 1.61 & 1.21 & 1.49 \\
\hline \multicolumn{5}{|l|}{ Grain mass (mg) } \\
\hline Mean & 9.3 & 7.2 & 5.8 & 7.4 \\
\hline Minimum & 8.2 & 6.1 & 4.7 & 6.3 \\
\hline Maximum & 10.2 & 8.0 & 6.7 & 8.3 \\
\hline SED (progeny) & 0.24 & 0.26 & 0.27 & 0.26 \\
\hline \multicolumn{5}{|l|}{ Harvest index (\%) } \\
\hline Mean & 44.8 & 40.2 & 32.4 & 39.1 \\
\hline Minimum & 40.9 & 34.9 & 28.2 & 34.7 \\
\hline Maximum & 49.0 & 45.2 & 37.8 & 44.1 \\
\hline SED (progeny) & 0.98 & 1.45 & 1.51 & 0.83 \\
\hline \multicolumn{5}{|c|}{ Panicle harvest index (\%) } \\
\hline Mean & 75.4 & 68.2 & 60.5 & 68.0 \\
\hline Minimum & 71.6 & 61.5 & 55.4 & 62.9 \\
\hline Maximum & 78.3 & 71.4 & 65.0 & 71.4 \\
\hline SED (progeny) & 0.82 & 1.33 & 1.82 & 0.91 \\
\hline
\end{tabular}

season is sufficiently stable, and the management of the drought nursery was sufficiently repeatable, that neither year nor year $\times$ moisture environment was a significant source of variation for any of the measured variables. The high degree of blocking in the experimental design was able to account for a significant part of the local field variability (Table 1), which, given the size of the experiment, would have been expected.

\section{Progeny and Progeny $\times$ Moisture Environment Interactions}

Progeny differences were significant for all variables reported (Table 1), and the ranges in the progeny BLUPs across all three moisture environments varied widely (Table 2). Thus, despite the relatively small number of mapped progenies used, plus the fact that $50 \%$ of the genome of each test-crossed progeny was similar, the variation among test-crossed progenies for yield and yield components across a range of grain-filling moisture environments was substantial. Differences among progenies under terminal stress were expected because of the differential tolerance of such stress between the parents of the mapping population, but the range in progeny values was generally as large in the favorable environment as it was in the drought-stressed ones (Table 2).

Progeny $\times$ moisture environment interactions were, somewhat surprisingly, significant only for $\mathrm{HI}$ and PNHI (Table 1). Differences among related, elite genetic materials in HI and PNHI are often small in the absence of stress, but become greater as stress affects seed set, seed filling, and assimilate supply to the grain differentially in different genotypes; so interactions with moisture environment are expected in these two variables. The lack of significant progeny $\times$ moisture environment interactions for GRYLD, GRNO, or GRMA is surprising, and suggests that the primary differences among progenies for these variables were constitutive ones, which were little affected by moisture environment during grain filling. This conclusion was supported by a strong similarity in ranking of individual progeny test crosses across the three grain-filling moisture environments: rank correlation coefficients for GRYLD were $\geq 0.88$ and for GRNO and GRMA $\geq 0.97$ (data not presented). This is a positive finding in the context of this research, i.e., if potential yield differences are more important in determining realized yield in the stress environments than is stress tolerance, the chance of finding effective across-environment QTLs are greater. However, QTLs for traits related to stress tolerance are still of interest, especially when these are significantly correlated to grain yield in severe stress environments (Table 3 ).

Progeny $\times$ year interactions were significant for GRNO and GRMA, but not for GRYLD (Table 1), which suggests that the year effects on the two major yield components were of a compensatory nature, i.e., an increase in one was 
offset by a decrease in the other, with the net result that GRYLD itself was unaffected. Progeny $\times$ year interactions were also significant for $\mathrm{HI}$ and PNHI, but again not associated with a parallel interaction for GRYLD. Thus in both cases (moisture environment and year), the environmental response of HI and PNHI did not appear to be strongly linked to the response of GRYLD.

\section{Relationships of Yield and Component Variables}

The questions of the relationship of grain yield with both the basic yield components and the indicators of stress response (plus the effects of moisture environment on the relationships) were examined by correlation of grain yield and the component and indicator variables within and across moisture environments. The two basic yield components (GRNO and GRMA) were significantly, but only very modestly, related to grain yield across environments, with variation in both components explaining approximately $20 \%$ of the variation in GRYLD (Table 3). As grain-filling stress increased (i.e., earlier stress onset), the importance of GRNO to GRYLD declined slightly, and the importance of GRMA increased slightly (Table 3), but in neither case were the changes striking. In contrast, the across-environment relationships of GRYLD with both $\mathrm{HI}$ and PNHI were considerably stronger, with variation in HI explaining $44 \%$ of the variation in GRYLD and that in PNHI explaining 52\% (Table 3). In both cases, the strength of the relationship of GRYLD and the stress response indicator variable increased with increasing stress severity; correlation coefficients increased from 0.51 to 0.76 in the case of $\mathrm{HI}$ and from 0.57 to 0.79 in the case of PNHI (Table 3). This suggests that genotype differences in $\mathrm{HI}$ and especially PNHI are useful indicators of genotype differences in adaptation to stress, as measured by genotype grain yield. It is not clear therefore why progeny $x$ moisture environment interactions in $\mathrm{HI}$ and PNHI were not reflected in parallel progeny $\times$ moisture environment interactions in GRYLD. On the strength of the behavior of the correlations of GRYLD with both HI and PNHI, however, we mapped QTLs for these variables, along with GRYLD, GRNO, and GRMA, both within and across grain-filling moisture environments.

\section{Quantitative Trait Loci for Grain Yield and Component Traits Grain Yield}

Quantitative trait loci for mean GRYLD across moisture environments were mapped on LG 2, LG 3, and LG 4 (Table 4). The GRYLD QTLs on LG 2 also mapped in each of the three individual moisture environments. Those on LG 3 and LG 4 mapped in just the late-onset stress environment (Table 4), which suggests that they are primarily associated with yield differences under terminal stress.
Table 3. Pearson correlation coefficients of the test-crossed $\mathrm{F}_{4}$ progeny grain yield and yield components for individual grain-filling moisture environment and for mean values across all moisture environments.

\begin{tabular}{|c|c|c|c|c|}
\hline \multirow[b]{2}{*}{$\begin{array}{l}\text { Grain } \\
\text { yield vs. }\end{array}$} & \multicolumn{4}{|c|}{ Pearson correlation coefficients } \\
\hline & $\begin{array}{l}\text { Favorable } \\
\text { conditions }\end{array}$ & $\begin{array}{c}\text { Moderate, } \\
\text { late-onset } \\
\text { stress }\end{array}$ & $\begin{array}{l}\text { Severe, } \\
\text { early-onset } \\
\text { stress }\end{array}$ & $\begin{array}{c}\text { Across } \\
\text { moisture } \\
\text { environments }\end{array}$ \\
\hline Grain number & $0.492^{\star \star}$ & $0.443^{\star \star}$ & $0.398^{\star \star}$ & $0.445^{\star \star}$ \\
\hline Grain mass & $0.378^{\star \star}$ & $0.495^{\star \star}$ & $0.587^{\star \star}$ & $0.493^{\star \star}$ \\
\hline Harvest index & $0.514^{\star *}$ & $0.702^{\star \star}$ & $0.761^{\star \star}$ & $0.661^{\star *}$ \\
\hline $\begin{array}{l}\text { Panicle harvest } \\
\text { index }\end{array}$ & $0.574^{\star \star}$ & $0.742^{\star \star}$ & $0.792^{\star *}$ & $0.724^{\star *}$ \\
\hline
\end{tabular}

${ }^{* *}$ Significant at $P<0.01$.

Neither had a significant QTL $\times$ environment $(\mathrm{Q} \times \mathrm{E})$ interaction, however, so their benefit under terminal stress is not likely to be at the cost of GRYLD in the absence of stress, even if the effect is greater in stress environments. The LG 2 QTL (linked to markers Xpsm458-Xpsmp2059, Genomic Region 2, Fig. 1) was the most interesting, as it had substantial LOD scores in all three moisture environments (6.3-6.9) as well as across environments (7.9) and accounted for a significant proportion of the phenotypic variance for GRYLD in both the stress $(27-38 \%)$ and the stress-free $(28 \%)$ environments, as well as in the means across environments (25\%, Table 4). The favorable allele at this locus was from 863B. The LG 3 and LG 4 QTLs had lower LOD scores and accounted for much smaller fractions of the phenotypic variance for GRYLD, both in the late-onset stress environment and across environments, than did the LG 2 QTL. The favorable alleles at both of these loci were from ICMB 841.

\section{Grain Number}

One strong QTL for GRNO was mapped on LG 1 (Genomic Region 1) across moisture environments, with the favorable allele from ICMB 841 (Table 4). The LOD scores in the three moisture environments ranged from 7.7 to 9.3 (7.8 for the means across environments); this QTL accounted for $34 \%$ of phenotypic variation across environments and between 34 and $41 \%$ in individual moisture environments. Despite being detected in all environments, and thus appearing to be a broadly effective QTL (i.e., little affected by moisture environment) the $\mathrm{Q} \times \mathrm{E}$ analysis did indicate a significant $(P \leq 0.05)$ interaction with environment (Table 4). Presumably this was a consequence of differences in the magnitude of effects in different moisture environments, as no crossover interaction was observed. Noncrossover $\mathrm{Q} \times \mathrm{E}$ interaction is commonly due to either inconsistency in detection of QTLs in different environments or differential levels of expression of QTLs in different environments (Veldboom and Lee, 1996; Austin and Lee, 1998; Li et al., 2003). As potential GRNO is largely determined before actual flowering, when the stress 
Table 4. Quantitative trait loci (QTLs) identified for grain yield and yield component traits for individual grain-filling moisture environments and for mean across moisture environments $\left(R^{2}\right.$ adj is the fraction of the phenotypic variation in the trait explained by the individual QTL; the additive effect is half the difference between the genotypic values of the two homozygotes at the locus in question; a positive sign of additive effect indicates $863 \mathrm{~B}$ allele favors the QTL; probability of $\mathrm{Q} \times \mathrm{E}$ is the probability of the QTL × moisture environment interaction occurring by chance).

\begin{tabular}{|c|c|c|c|c|c|c|c|c|c|c|c|}
\hline \multirow[b]{2}{*}{ Trait } & \multirow[b]{2}{*}{$\mathrm{LG}^{+}$} & \multirow[b]{2}{*}{ Marker interval } & \multicolumn{2}{|c|}{$\begin{array}{l}\text { Stress-free } \\
\text { environment }\end{array}$} & \multicolumn{2}{|c|}{$\begin{array}{l}\text { Late-stress } \\
\text { environment } \\
\end{array}$} & \multicolumn{2}{|c|}{$\begin{array}{l}\text { Early-stress } \\
\text { environment }\end{array}$} & \multicolumn{3}{|c|}{$\begin{array}{c}\text { Across moisture } \\
\text { environments }\end{array}$} \\
\hline & & & $\begin{array}{l}\text { LOD } \\
\left(R_{\text {adj }}^{2}\right)\end{array}$ & $\begin{array}{c}\text { Additive } \\
\text { effect }\end{array}$ & $\begin{array}{l}\text { LOD } \\
\left(R_{\text {adj }}^{2}\right)\end{array}$ & $\begin{array}{c}\text { Additive } \\
\text { effect }\end{array}$ & $\begin{array}{l}\text { LOD } \\
\left(R_{\text {adj }}^{2}\right)\end{array}$ & $\begin{array}{c}\text { Additive } \\
\text { effect }\end{array}$ & $\begin{array}{l}\text { LOD } \\
\left(R_{\text {adj }}^{2}\right)\end{array}$ & $\begin{array}{c}\text { Additive } \\
\text { effect }\end{array}$ & $\begin{array}{c}P \\
(\mathrm{Q} \times \mathrm{E})\end{array}$ \\
\hline \multirow[t]{5}{*}{ Grain yield, $\mathrm{g} \mathrm{m}^{-2}$} & 1 & Xpsmp2069-Xpsm756 & $2.5(11.3)$ & 4.73 & & & $2.7(20.4)$ & 5.7 & & & \\
\hline & 2 & Xpsm458-Xpsmp2050 & $6.3(28.2)$ & 7.78 & $6.3(26.5)$ & 6.4 & $6.9(37.6)$ & 8.1 & $7.9(24.7)$ & 6.0 & $N S^{\S}$ \\
\hline & 3 & Xpsm108-Xpsmp2214 & & & $2.8(11.6)$ & -3.7 & & & $3.1(12.6)$ & -3.7 & NS \\
\hline & 4 & Xpsm1003d-Xpsm1007c & & & $3.5(17.3)$ & -4.6 & & & $2.9(18.7)$ & -5.0 & 0.01 \\
\hline & 7 & Xpsmp2224-Xpsm717 & & & & & $2.8(12.1)$ & 4.1 & & & \\
\hline \multirow{2}{*}{$\begin{array}{l}\text { Grain number, } \\
\text { no. } \times 10^{3} \mathrm{~m}^{-2}\end{array}$} & 1 & Xpsm761-Xpsm756 & $7.7(33.8)$ & -1324 & $7.8(33.8)$ & -1306 & $9.3(40.8)$ & -1349 & $7.8(33.5)$ & -1283 & 0.01 \\
\hline & 4 & Xpsm1003d-Xpsm1007c & & & & & $4.2(17.0)$ & -760 & & & \\
\hline \multirow[t]{4}{*}{ Grain mass, mg } & 1 & Xpsm761-Xpsm756 & $7.9(41.4)$ & 0.4 & $6.8(33.7)$ & 0.4 & $6.9(57.2)$ & 0.4 & $7.8(40.2)$ & 0.4 & NS \\
\hline & 2 & Xpsm322-Xpsmp2059 & & & & & $6.6(34.6)$ & 0.3 & & & \\
\hline & 3 & Xpsm108-Xpsmp2214 & $3.0(16.7)$ & -0.2 & & & $4.3(17.6)$ & -0.2 & $2.9(16.2)$ & -0.2 & 0.01 \\
\hline & 6 & Xpsm588-Xpsm713 & & & & & $3.0(6.1)$ & 0.1 & & & \\
\hline \multirow[t]{5}{*}{ Harvest index, \% } & 2 & $\begin{array}{l}\text { Xpsmp2066- } \\
\text { Xpsmp2059 }\end{array}$ & $2.7(13.6)$ & 0.7 & $4.6(20.5)$ & 1.0 & $10.0(37.6)$ & 1.7 & $8.1(25.7)$ & 1.1 & 0.01 \\
\hline & 3 & Xpsm108-Xpsmp2214 & $6.1(18.1)$ & -0.8 & $5.7(23.0)$ & -1.0 & $5.6(16.6)$ & -0.8 & $7.6(29.2)$ & -1.0 & NS \\
\hline & 4 & Xpsm1003d-Xpsm1007c & & & $2.8(6.7)$ & -0.5 & & & & & \\
\hline & 5 & Xpsmp2064-Xpsm318 & & & $3.1(13.5)$ & 0.9 & & & $2.6(15.9)$ & 0.7 & 0.01 \\
\hline & 7 & Xpsmp2224-Xpsm717 & $5.5(34.5)$ & 1.5 & $4.8(31.7)$ & 1.5 & $3.4(27.9)$ & 1.3 & 4.9 (29.9) & 1.2 & 0.05 \\
\hline \multirow{4}{*}{$\begin{array}{l}\text { Panicle harvest } \\
\text { index, \% }\end{array}$} & 1 & Xpsm761-Xpsm756 & $3.1(13.4)$ & 0.7 & $6.4(29.3)$ & 1.3 & $5.7(44.0)$ & 1.8 & $5.3(40.5)$ & 1.3 & 0.01 \\
\hline & 2 & $\begin{array}{l}\text { Xpsmp2059- } \\
\text { Xpsmp2050 }\end{array}$ & & & $9.7(42.8)$ & 1.7 & $6.2(51.4)$ & 2.0 & $6.0(50.8)$ & 1.6 & 0.01 \\
\hline & 3 & Xpsm108-Xpsmp2214 & $3.5(19.9)$ & -0.8 & $3.8(14.0)$ & -0.7 & $5.8(25.0)$ & -1.0 & $6.0(25.2)$ & -0.8 & NS \\
\hline & 6 & Xpsm588-Xpsm713 & & & & & $4.9(17.3)$ & 1.0 & $5.1(18.4)$ & 0.8 & NS \\
\hline
\end{tabular}

$+\mathrm{L} G$, linkage group.

‡LOD, logarithm of odds.

§NS, not significant at 0.05

environment differences began, the significant across-environment effect of a GRNO QTL was expected.

This QTL co-mapped with a GRYLD QTL for both favorable and moderate stress environments, and with a GRMA QTL in all three individual moisture environments (Table 4). The favorable allele in the case of both the GRYLD and GRMA co-mapped QTLs was contributed by $863 \mathrm{~B}$, however, not ICMB 841 as was the case for the GRNO QTL. Thus the ICMB 841 allele at this QTL may be linked to a smaller grain size, as GRNO and GRMA are commonly negatively correlated in the crop (Bidinger et al., 2001). Because the importance of GRMA to GRYLD increases as stress becomes more severe (Table 3), it is the 863B allele at this QTL, linked to larger GRMA, which is likely to be the more favorable for maintaining GRYLD under severe stress. Thus if this QTL were considered for use in yield improvements across a range of moisture environments, it would be the 863B allele, with its favorable effect on GRMA under stress, not the ICMB 841 allele with its favorable effect on GRNO, that would be the choice for selection.

\section{Individual Grain Mass}

There were two QTLs for GRMA detected across moisture environments, one on LG 1 and one on LG 3, one of which (LG 3) had significant $Q \times E$ interaction (Table 4). The QTL on LG 1 (Genomic Region 1, Fig. 1) explained a very significant proportion $(40 \%)$ of the phenotypic variance of the mean GRMA across environments, with significant effects in both the stress-free and mild-stress environments, where it explained $\geq 40 \%$ of the phenotypic variance for GRMA, and a very strong effect in the severe-stress environments, where it explained $57 \%$ of the phenotypic variance for this trait (Table 4). In all cases, the favorable allele was contributed by the drought-tolerant parent $863 \mathrm{~B}$. The LG 3 QTL accounted for a much smaller proportion of the mean variance in GRMA across environments (16\%, Table 4). Its effect was similar in the favorable and severe-stress conditions (LOD scores of 3.0-4.3, with additive effects of the ICMB 841 allele of $0.2 \mathrm{mg}$ grain $^{-1}$ ) but it was not detected in the moderate-stress environments. There was also a moderately strong GRMA QTL in LG 2 detected in the severe-stress environments, but it was not detected in 
LG 1

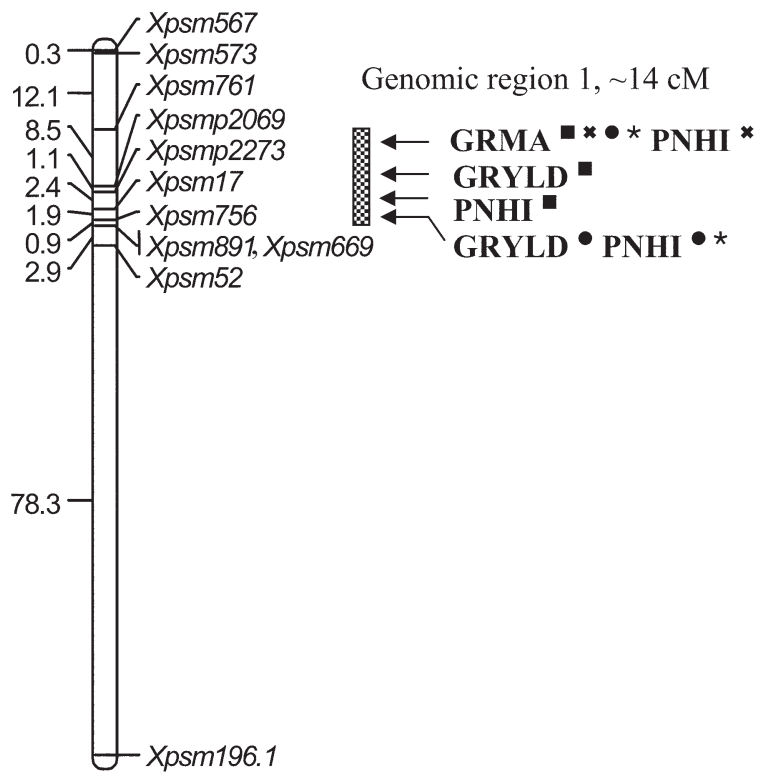

LG 3

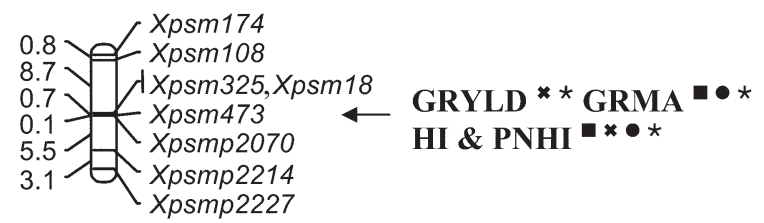

LG 2

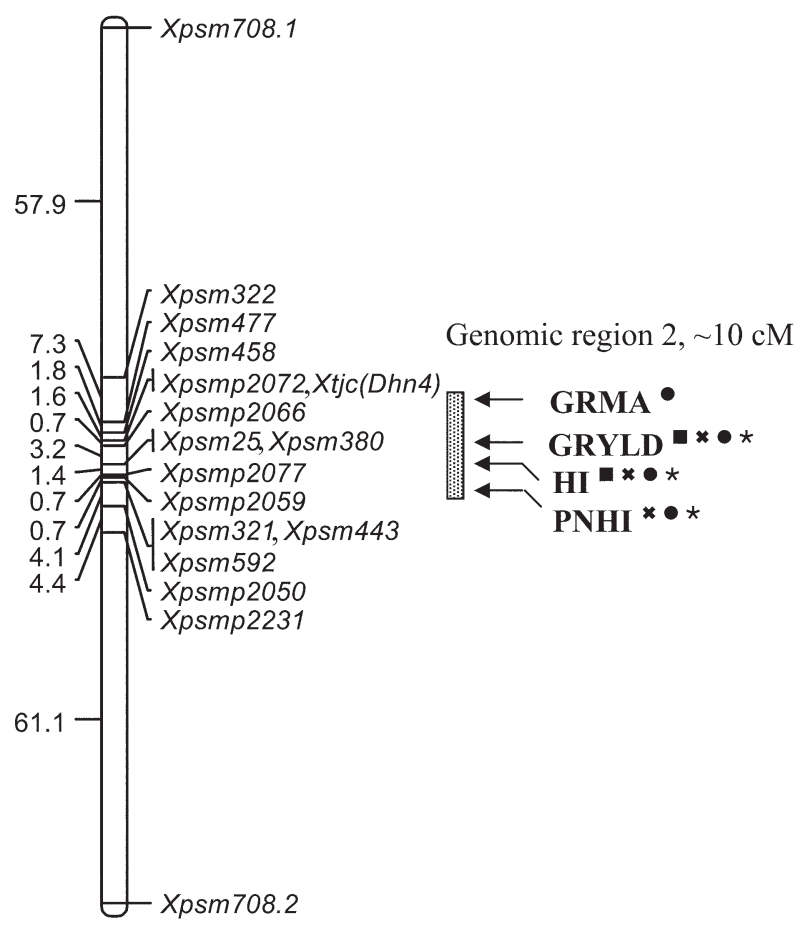

- irrigated control

* late-onset stress

- early-onset stress

* across moisture environments

Figure 1. Pearl millet linkage groups 1, 2, and 3, based on the $F_{2}$ mapping population derived from ICMB $841 \times 863 B$, with quantitative trait locus peaks (indicated by arrow) for grain yield and linked traits, sharing common genomic regions (proposed for marker-assisted selection for broader adaptability), mapped at various moisture environments. Loci positions are given in Haldane cM to the left of the linkage groups (GRYLD: grain yield; GRMA: grain mass; HI: harvest index; PNHI: panicle harvest index).

the other environments and not detected across environments (Table 4).

All three of these GRMA QTLs co-mapped with QTLs for GRYLD, but only the co-mapped GRYLD QTLs on LG 2 and LG 3 were detected across environments (Table 4). These two QTLs each accounted for a useful proportion of the phenotypic variance for mean GRYLD across all environments (25\% by the LG 2 QTL and $13 \%$ by the LG 3 QTL). The strongest effects of the LG 2 GRMA QTL on GRYLD was in the early-onset stress environment, where it accounted for 35 and $38 \%$ of the phenotypic variance for GRMA and GRYLD, respectively (Table 4), confirming the effectiveness of the LG 2 QTL under severe stress. The strong LG 1 GRMA QTL had a smaller effect on grain yield, despite its stronger effect on GRMA (Table 4).

\section{Harvest Index}

Harvest index in this experiment was used as a measure of genotype adaptation to various moisture environments during grain filling, expressed as the ability to maximize partitioning of total biomass to grain yield, despite varying levels of current photosynthesis for grain filling. Four
QTLs were detected for across-environment HI, one each on four of the seven pearl millet LGs (Table 4). Percentage of the phenotypic variance for across-environment $\mathrm{HI}$ accounted for by the individual QTLs ranged from 15 to $30 \%$. Except for the QTL on LG 3, the favorable alleles for HI QTLs were contributed by 863B. Three of the four HI QTLs were subject to significant $Q \times E$ interaction, consistent with the significant genotype $\times$ environment interaction found for the trait itself (Table 1). Of these three, the first (on LG 2) appeared to be primarily a drought-tolerance QTL, as the proportion of variance in $\mathrm{HI}$ it explained (14-38\%) increased as moisture stress increased (Table 4). This QTL co-mapped with QTLs for both GRYLD and GRMA that showed similar patterns of effects across the three moisture environments. The second HI QTL (on LG 5 ) was detected only in one moisture environment (earlyonset stress) and across environments, and did not co-map with across-environment QTLs for GRYLD, GRNO, or GRMA (Table 4), and thus appears to be of secondary interest. The third HI QTL (on LG 7) accounted for a slightly greater proportion of the phenotypic variance for $\mathrm{HI}$ in the stress-free environments $(35 \%)$ than in the stress environments or the mean across environments 
(approximately 30\%). It also did not co-map with QTL for across-environment GRYLD or its components, however, and is thus also of secondary interest, despite its strong effect on HI. The one HI QTL that was not subject to Q $\times$ E interaction, on LG 3, accounted for a similar proportion of the phenotypic variance (17-23\%) in all three moisture environments, and $29 \%$ of the variance in the mean across all environments (Table 4). This HI QTL also co-mapped with QTLs for GRMA and GRYLD, which also showed a similarly consistent effects in all the environments in which the HI QTL was mapped.

The two most useful of the HI QTLs thus appear to be those on LG 2 and LG 3, both of which appear to affect grain filling (GRMA), and both of which co-map with GRYLD QTLs but have different environmental expressions. The LG 2 HI QTL appears to be primarily a drought-tolerance QTL, with a significant $\mathrm{Q} \times \mathrm{E}$ interaction, but still with a strong effect on the mean across environments, and the favorable allele from 863B. The LG $3 \mathrm{HI}$ QTL has less environment-specific effects (no $\mathrm{Q} \times \mathrm{E}$ interaction), with moderate effects in the individual moisture environments and a strong effect across environments, and with the favorable allele contributed by ICMB 841.

\section{Panicle Harvest Index}

Panicle harvest index in this experiment was used specifically as a measure of tolerance to terminal drought, expressed as the ability to set and fill grains under limited moisture. Four across-moisture-environment PNHI QTLs were identified, of which two, on LG 1 and LG 2, each accounted for nearly half of the phenotypic variance in PNHI across environments (Table 4). Both of these appeared to be primarily stress-tolerance QTLs, accounting for a higher proportion of phenotypic variance in the stress environments than in the stress-free ones, and both showing significant $Q \times E$ interactions. The favorable allele at both QTLs was from 863B. The LG 1 PNHI QTL co-mapped with an across-environment GRMA QTL, which also expressed more strongly in the severestress environments, but which did not show a significant $\mathrm{Q} \times \mathrm{E}$ interaction (Table 4). The LG 2 PNHI QTL comapped with across-environment QTLs for GRYLD and HI, which similarly expressed more strongly in the stress environments. The co-mapping of PNHI QTL with both GRMA QTL and HI QTL is not unexpected under grain-filling moisture stress.

The other two across-environment PNHI QTLs (LG 3 and LG 6) did not have significant $\mathrm{Q} \times \mathrm{E}$ interactions, but accounted for a lower proportion (25 and 18\% respectively) of the mean phenotypic variance in PNHI across environments than did the QTLs on LG 1 and LG 2 (Table 4). The PNHI QTL on LG 3, for which the favorable allele was from ICMB 841, was detected in all three moisture environments as well as across environments. It co-mapped with across-environment QTLs for GRYLD, HI, and GRMA, but only the HI QTL also had a nonsignificant $\mathrm{Q} \times \mathrm{E}$ interaction (Table 4). The PNHI QTL on LG 6, with the favorable allele from 863B, was detected only in the severe-stress environment and across environments. It co-mapped with a QTL for GRMA, which also expressed only under severe-stress conditions.

\section{Relationships to Previously Identified Quantitative Trait Loci}

Using the same mapping population and genotyping data, with only $2 \mathrm{yr}$ of stress environment phenotyping data but two testers, Yadav et al. (2004) mapped QTLs for grain yield and yield-related traits under terminal stress (indicated as stress-tolerance QTLs). The QTLs for GRYLD on LG 1 and LG 2, for HI on LG 2 and LG 3, and for PNHI on LG 1, LG 2, and LG 3 were identified in both studies, with similar positions on these LGs, despite the different QTL mapping programs used in this study (PLABQTL 1.1) and the study of Yadav et al. (2004) (Mapmaker/QTL 1.1). The two studies differed in the nature of $Q \times E$ interactions found, however. In the earlier study (Yadav et al., 2004), QTLs were mapped for individual years of testing, which identified some $\mathrm{Q} \times \mathrm{E}$ interactions that were of the crossover type. In this study, all $\mathrm{Q} \times \mathrm{E}$ interactions were due to differences in the magnitude of QTL effects in different environments, despite the fact that this study included a wider range of moisture environments than did the earlier study. The QTLs with non-crossover Q $\times$ $E$ interactions are preferable in a marker-based breeding program, as the target allele has a similar effect in different environments (although these may differ in magnitude). With crossover $\mathrm{Q} \times \mathrm{E}$ interactions, different alleles condition favorable performance in different environments, so that a gain in one environment may be offset by a loss in a contrasting environment.

This study also extends the information on the common QTLs identified in the two studies. The major LG 2 GRYLD QTL (863B allele) identified in both studies is clearly not simply a drought-tolerance QTL, as earlier reported, as it has a highly significant effect on GRYLD across all three moisture environments, including the stress-free environments (Table 4). This QTL co-maps with a strong QTL for HI across environments, suggesting that its major effect is a general increase in partitioning of biomass to grain. The general effect of this QTL on partitioning is also expressed under terminal stress in terms of a highly significant effect on PNHI (explaining $40-50 \%$ of the phenotypic variance), which underlines the particular value of better partitioning to grain under conditions of limited assimilate availability.

This study has also clarified the nature of and the reasons for the limited utility of the QTL on LG 1 (Table 4). The ICMB 841 allele at this QTL has a significant 
and consistent effect on GRNO both in the individual environments and across all environments (accounting for $34-41 \%$ of the variation for this trait). The increase in grain number is linked to a smaller grain size, however, which is expressed equally strongly in all three moisture environments and across environments (accounting for $33-57 \%$ of the variation for this trait) - hence the failure of this QTL to express as a GRYLD QTL across environments. In the severe-stress environment, the $863 \mathrm{~B}$ allele at this QTL accounted for a substantial portion (20\%) of the phenotypic variance for GRYLD through its very strong effect on GRMA. Across environments, however, this QTL has limited value (although the 863B allele at least had no negative effects on GRYLD in any of the three moisture environments).

The LG 3 HI and PNHI QTL detected in this study was also detected in the study of Yadav et al. (2004), but only across environments, and only for these two traits. This study strengthens the value of this QTL considerably, as it is now shown to have a significant effect on both traits in all three moisture environments, as well across environments, plus a significant (if modest) effect on both GRMA and GRYLD across environments. Finally, this study has identified two additional across-environment QTLs (LG 4 and LG 6), one of which may be of value in MAS. The LG 4 GRYLD QTL, with the favorable allele from ICMB 841, accounts for very useful 19\% of the variation in this trait across environments (Table 4). This QTL does not co-map with any other observed trait across environments, so it is not clear how it achieves its effect on GRYLD. Despite its significant $\mathrm{Q} \times \mathrm{E}$ interaction, however, the favorable allele from widely accepted ICMB 841 is of interest for MAS. The LG 6 PNHI and GRMA QTL, with the favorable allele from 863B, expresses mainly in the severe-stress environment and thus appears to be a secondary drought-tolerance QTL (Table 4).

\section{Selection of Quantitative Trait Loci for Marker-Assisted Selection}

Marker-assisted selection is clearly limited to a small number of target QTLs, as population sizes and costs for marker analyses increase significantly as target QTL numbers increase. Therefore it is important to select QTL targets for MAS on the basis of as much information as possible. The primary considerations in selection of target QTLs are (i) their likely direct (on the target trait) and indirect (on other traits) effects, and (ii) the expected stability of expression of the QTL across environments. The likely direct effects of selection for the favorable allele (in a homozygous condition) at a target QTL can be estimated as twice the additive effect of the allele, as determined from the analysis of the mapping population data. The QTL effect was estimated for both the main and comapped traits affected by each QTL, for the unstressed environment, the combined drought-stressed environments, and for all environments (Table 5). The expected stability across environments was assessed from the presence and nature of $\mathrm{Q} \times \mathrm{E}$ interactions in multi-environment QTL analyses (Table 4).

\section{Primary Quantitative Trait Loci}

Based on the estimated effects on target traits and the absence of $\mathrm{Q} \times \mathrm{E}$ interaction (Table 4), the $863 \mathrm{~B}$ allele at the QTL on LG 2 is the first target for MAS for adaptation

Table 5. Direct and indirect effects of candidate quantitative trait loci (QTLs) for the improvement of grain yield across a range of grain-filling moisture environments under moderate to severe grain-filling drought stress and in the absence of stress. Expected effects are based on the target QTL being homozygous for the positive allele, i.e., the expected effect will be twice the additive effect of the allele (GRYLD: grain yield; GRMA: grain mass; HI: harvest index; PNHI: panicle harvest index).

\begin{tabular}{|c|c|c|c|c|c|}
\hline \multirow[b]{2}{*}{$\begin{array}{l}\text { Linkage } \\
\text { group }\end{array}$} & \multirow[b]{2}{*}{$\begin{array}{l}\text { Targeted genomic } \\
\text { region }\end{array}$} & \multirow[b]{2}{*}{$\begin{array}{l}\text { Source } \\
\text { allele }\end{array}$} & \multicolumn{3}{|c|}{ Expected effect of selecting for target allele } \\
\hline & & & $\begin{array}{l}\text { Across moisture } \\
\text { environments }\end{array}$ & Grain-filling drought stress & Stress-free environments \\
\hline \multicolumn{6}{|c|}{ Primary QTLs } \\
\hline 2 & $\begin{array}{l}\text { Genomic region } 2 \\
\text { (Xpsm322-Xpsmp2059) }\end{array}$ & $863 B$ & $\begin{array}{l}\text { Increase in GRYLD of } 12 \mathrm{~g} \mathrm{~m}^{-2} \text {, } \\
\text { in } \mathrm{HI} \text { of } 2.2 \% \text {, in PNHI of } 3.2 \%\end{array}$ & $\begin{array}{l}\text { Increase in GRYLD of } \leq 16 \mathrm{~g} \mathrm{~m}^{-2} \text {, in } \\
\text { GRMA of } \leq 0.6 \mathrm{mg}_{\text {grain }}^{-1} \text {, in } \mathrm{HI} \text { of } \\
\leq 3.4 \% \text {, in } \mathrm{PNHI} \text { of } \leq 4.0 \%\end{array}$ & $\begin{array}{l}\text { Increase of } 16 \mathrm{~g} \mathrm{~m}^{-2} \text { in } \\
\text { GRYLD and } 1.4 \% \text { in } \mathrm{HI}\end{array}$ \\
\hline 3 & Xpsm108-Xpsmp2214 & ICMB 841 & $\begin{array}{l}\text { Increase in GRYLD of } 7.4 \mathrm{~g} \mathrm{~m}^{-2} \text {, } \\
\text { in GRMA of } 0.4 \mathrm{mg}_{\text {grain }}^{-1} \text {, in } \mathrm{HI} \\
\text { of } 2.0 \% \text {, in PNHI of } 1.6 \%\end{array}$ & $\begin{array}{l}\text { Increase in GRYLD of } \leq 7.4 \mathrm{~g} \mathrm{~m}^{-2} \text {, in } \\
\text { GRMA of } \leq 0.4 \mathrm{mg}_{\text {grain }}^{-1} \text {, in } \mathrm{HI} \text { and } \\
\text { PNHI of } \leq 2 \%\end{array}$ & $\begin{array}{l}\text { Increase in GRMA of } \\
0.4 \mathrm{mg} \text { grain }^{-1} \text {, in } \mathrm{HI} \text { and } \\
\mathrm{PNHI} \text { of } 1.6 \%\end{array}$ \\
\hline 4 & Xpsm1003d-Xpsm1007c & ICMB 841 & $\begin{array}{l}\text { Increase in GRYLD of } 10 \mathrm{~g} \mathrm{~m}^{-2} \text {, } \\
\text { but no effect on other traits }\end{array}$ & $\begin{array}{l}\text { Increase of } \leq 9 \mathrm{~g} \mathrm{~m}^{-2} \text { in GRYLD and } \\
\leq 1 \% \text { in } \mathrm{HI}\end{array}$ & No predicted effects \\
\hline \multicolumn{6}{|c|}{ Secondary QTLs } \\
\hline 1 & $\begin{array}{l}\text { Genomic region } 1 \\
\text { (Xpsm761-Xpsm756) }\end{array}$ & $863 \mathrm{~B}$ & $\begin{array}{l}\text { Increase in PNHI of } 2.6 \% \text { and in } \\
\text { GRMA of } 0.8 \mathrm{mg}^{\text {grain }}{ }^{-1}\end{array}$ & $\begin{array}{l}\text { Increase in PNHI of } \leq 3.6 \% \text {, in GRMA of } \\
0.8 \mathrm{mg}_{\text {grain }}^{-1} \text {, in GRYLD of } \leq 11 \mathrm{~g} \mathrm{~m}^{-2}\end{array}$ & $\begin{array}{l}\text { Increase in PNHI of } 1.4 \% \text {, in } \\
\text { GRMA of } 0.8 \mathrm{mg} \mathrm{grain}^{-1} \text {, } \\
\text { in GRYLD of } 9 \mathrm{~g} \mathrm{~m}^{-2}\end{array}$ \\
\hline 7 & Xpsmp2224-Xpsm717 & 863B & Increase in $\mathrm{HI}$ of $2.4 \%$ & $\begin{array}{l}\text { Increase in PNHI of } 2.6-3.0 \% \text {, in } \\
\text { GRYLD of } \leq 8 \mathrm{~g} \mathrm{~m}^{-2}\end{array}$ & Increase in $\mathrm{HI}$ of $3.0 \%$ \\
\hline 6 & Xpsm588-Xpsm713 & 863B & Increase in $\mathrm{PNHI}$ of $1.6 \%$ & $\begin{array}{l}\text { Increase in PNHI of } \leq 2.0 \% \text {, in GRMA } \\
\text { of } \leq 0.2 \mathrm{mg} \mathrm{grain}^{-1}\end{array}$ & No predicted effects \\
\hline
\end{tabular}


to varying moisture environments during grain filling. This QTL was also identified by Yadav et al. (2004) for improving terminal stress tolerance, based on its favorable effects in terminal stress environments. The projected effect of selection for this QTL include an increase in GRYLD of $12 \mathrm{~g} \mathrm{~m}^{-2}$ across all environments, plus major gains in both GRMA and PNHI (Table 5). For individual environments, incorporating this QTL results in a predicted gain of $16 \mathrm{~g} \mathrm{~m}^{-2}$ in the absence of stress and 13 to $16 \mathrm{~g} \mathrm{~m}^{-2}$ in the terminal stress environments. This is accompanied by predicted gains in HI $(2.2 \%)$ and PNHI (3.2\%) across environments (Table 5).

The second target QTL for MAS would probably be the ICMB 841 allele at either of the GRYLD QTLs on LG 3 (linked to marker Xpsm108) or LG 4 (linked to marker Xpsm1003d), both of which have a significant effect on across-environment GRYLD (Table 5). Despite their being detected on the basis of across-environment effects, both appear to be primarily drought-tolerance QTLs, as the only individual environment in which they had a significant effect on GRYLD was the late-stress environment (Table 4). Selection for the ICMB 841 allele at LG 3 has a predicted effect of increasing GRYLD by $7.4 \mathrm{~g} \mathrm{~m}^{-2}$ across environments, as well as under moderate stress, and of increasing $\mathrm{HI}$ and PNHI by between 1.6 and 2\% (in absolute terms) both across environments and in all individual environments (Table 5). Selection for the ICMB 841 allele at LG 4 had predicted effects of increasing GRYLD by $10 \mathrm{~g}$ $\mathrm{m}^{-2}$ across environments and by up to $9.2 \mathrm{~g} \mathrm{~m}^{-2}$ in the moderate-stress environment, but was subject to a significant $\mathrm{Q}$ $\times$ E interaction (Table 5). As both the LG 3 and LG 4 alleles have generally similar predicted effects on grain yield across environments, the choice comes down to the improvement in either individual environments, individual traits, or the expected $\mathrm{Q} \times \mathrm{E}$ interaction. All of these factors favor the LG 3 QTL. It has a predicted favorable effect on both HI and PNHI across environments, favorable effects on several traits in the stress-free environment, and nonsignificant $\mathrm{Q}$ $\times$ E interaction, none of which were true for the LG 4 QTL (Tables 4 and 5).

\section{Secondary Quantitative Trait Loci}

There were several additional strong QTLs for acrossenvironment traits that did not have significant or direct effects on GRYLD in the test environments, despite the positive correlations of grain yield and all of the traits for which QTLs were identified (Table 3). The first of such QTLs is the GRMA and PNHI QTL on LG 1, with a favorable allele from 863B. Marker-assisted selection for this allele at this QTL predicted an increase in both traits across environments, as well as in most individual environments (Table 5); however, its effect on GRYLD was not consistent among individual environments. Its LOD score (2.4) for GRYLD was just below the minimum nec- essary to be considered as effective across environments, and its $\mathrm{Q} \times \mathrm{E}$ interaction would have been significant had it been identified across environments. (The reason is probably the offsetting effects of the alternate $863 \mathrm{~B}$ and ICMB 841 alleles at this locus, the former of which had a beneficial effect on GRMA and latter a beneficial effect on GRNO). Therefore this QTL would be less useful for MAS than the primary QTLs above.

The next of the secondary QTLs is the strong acrossenvironment HI QTL on LG 7 (linked to marker Xpsm717), with the favorable allele from 863B. The predicted effect of selection for this QTL ranged from a gain of 2.6 to $3.0 \%$ in $\mathrm{HI}$ (in absolute terms) in individual environments and $2.4 \%$ across moisture environments, and an increase GRYLD by $8 \mathrm{~g} \mathrm{~m}^{-2}$ in the severe-stress environment, where there was a strong correlation of $\mathrm{HI}$ and grain yield (Table 3). This makes this QTL of potential interest for strengthening adaptation to more serious stress environments (i.e., for improving drought tolerance). The third of the secondary QTL is the relatively strong PNHI QTL on LG 6 (linked to marker Xpsm588), with the favorable allele again from 863B. Because of the large predicted gain in PNHI from MAS for this QTL (Table 5), it may have value for the improvement of partitioning to grain under terminal stress, without a cost in stress-free environments; however, this QTL would be of less interest for improving GRYLD across a range of environments.

Two other criteria need to be considered in choosing among potential target QTLs for MAS: (i) the availability of easily scored marker polymorphism at loci flanking the QTL; and (ii) confidence in the QTL (related both to the complexity of genetic and environmental factors controlling the trait and to the power of the QTL detection experiment [mapping population size, marker numbers, and marker distribution]). Both of the primary QTLs (LG 2 and LG 3) are acceptable on both criteria. Genomic Region 2 (LG 2 for GRYLD, HI, and PNHI) has several closely linked markers (Xpsm322-Xpsmp2050, spanning the length of $14 \mathrm{cM}$ ) and a high level (as much as 0.92) of polymorphic information content (PIC) for the microsatellite markers (Qi et al., 2004), making this region very amenable to high-throughput genotyping. The LG 3 GRYLD, GRMA, HI, and PNHI QTL has linked marker Xpsm18, which is an RFLP, but it maps to almost the same position as SSR locus Xpsmp2070 (PIC of 0.90), so again this QTL also should be very amenable to MAS.

The pearl millet map is being constantly updated with newly developed SSR, expressed sequence tag SSR, single-strand conformational polymorphism-single nucleotide polymorphism, conserved-intron scanning primers, and target region amplified polymorphism based markers (C.T. Hash, personal communication, 2006). As a consequence, highly polymorphic polymerase chain reaction compatible markers will soon flank most of the RFLP 
markers that now anchor the pearl millet linkage map. Use of these newly added markers will reduce costs and time needed to exploit QTLs in targeted MAS programs for variable grain-filling moisture conditions.

\section{CONCLUSIONS}

This study was intended to identify QTLs linked to improved grain yield across a range of postflowering moisture environments, using data from a 4-yr phenotyping exercise done in a managed, field drought nursery, with annual stress-free, late-onset (moderate) terminal stress, and early-onset (severe) terminal stress treatments. The study was based on 79 skeleton mapped $\mathrm{F}_{2}$-derived $\mathrm{F}_{4}$ progenies from the cross of two maintainer lines, one widely adapted and one specifically adapted to terminal drought environments, crossed to a single tester. Data were collected on grain yield, yield components, and crop and panicle harvest indices. The phenotyping data set was ideal for the purpose, as progeny and moisture-environment variances were highly significant but year, year $\times$ progeny, and year $\times$ environment variances were not.

Three QTLs (on LG 2, LG 3, and LG 4) were identified as primary candidates for MAS for improved grain yield across variable postflowering moisture environments. The most promising of the three, those on LG 2 (863B allele) and LG 3 (ICMB 841 allele) explained a useful proportion ( 25 and $13 \%$, respectively) of phenotypic variance for GRYLD across environments (Table 5). They also co-mapped with QTLs for HI across environments, and with QTLs for GRMA, PNHI, and HI under severe terminal stress. Neither had a significant $\mathrm{Q} \times \mathrm{E}$ interaction, meaning that their predicted effects should occur across a broad range of available moisture environments. Finally, both are linked to SSR markers so they are amenable to efficient MAS. The remaining QTL (LG 4) is of secondary interest as it has a less consistent performance across individual moisture environments and a less clear effect on secondary traits. Responses to MAS predicted for each of the identified GRYLD QTLs ranged from 7 to $10 \mathrm{~g} \mathrm{~m}^{-2}$ (70-100 $\mathrm{kg} \mathrm{ha}^{-1}$ ) across environments and as much $16 \mathrm{~g} \mathrm{~m}^{-2}$ in individual moisture environments. Finally, this study has clarified the action and utility of several of the QTLs identified in an initial analysis of a subset (four of the 12 environments) of this data set (Yadav et al., 2004).

\section{Acknowledgments}

We would like to thank Mr.A. Ganapathi and Mr. P. Om Prakash for assistance in producing the mapping population and testcross seed of its progenies, and Mr. P.V.D. Maheshwar Rao for managing the drought nursery in a very efficient manner and collecting the majority of the field data. This document is an output from projects (Plant Sciences Research Programme R7375 and R8183) funded by the UK Dep. for International Development (DFID) and administered by CAZS Natural Resources for the benefit of developing countries. The views expressed are not necessarily those of DFID.

\section{References}

Allouis, S., X. Qi, S. Lindup, M.D. Gale, and K.M. Devos. 2001. Construction of BAC library of pearl millet, Pennisetum glaucum. Theor. Appl. Genet. 102:1200-1205.

Andrews, D.J., and K. Anand Kumar. 1996. Use of the West African pearl millet landrace Iniadi in cultivar development. Plant Genet. Resour. Newsl. 105:15-22.

Austin, D.F., and M. Lee. 1998. Detection of quantitative trait loci for grain yield and yield components in maize across generations in stress and nonstress environments. Crop Sci. 38:1296-1308.

Bidinger, F.R. 2002. Field screening for drought tolerance: Principles and illustrations. p. 109-124. In N.P. Saxena and J.C. O'Toole (ed.) Field screening for drought tolerance in crop plants with emphasis on rice. ICRISAT, Patancheru, India.

Bidinger, F.R., S. Chandra, and V. Mahalakshmi. 2000. Genetic improvement of tolerance to terminal drought stress in pearl millet [Pennisetum glaucum (L.) R. Br.]. p. 59-63. In J.M. Ribaut and D. Poland (ed.) Molecular approaches for the genetic improvement of cereals for stable production in water-limited environments. Strategic Planning Workshop, CIMMYT, El Batan, Mexico. 21-25 June 1999. CIMMYT, Mexico.

Bidinger, F.R., S. Chandra, and D.S. Raju. 2001. Genetic variation in grain filling ability in dwart pearl millet [Pennisetum glaucum (L.) R. Br.] restorer lines. Theor. Appl. Genet. 102:387-391.

Bidinger, F.R., and C.T. Hash. 2004. Pearl millet. p. 225-270. In H.T. Nguyen and A. Blum (ed.) Physiology and biotechnology integration for plant breeding. Marcel Dekker, New York.

Bidinger, F.R., V. Mahalakshimi, and G. Durga Prasada Rao. 1987a. Assessment of drought resistance in pearl millet [Pennisetum americanum (L.) Leeke]: I. Factors affecting yields under stress. Aust. J. Agric. Res. 38:37-48.

Bidinger, F.R., V. Mahalakshimi, and G. Durga Prasada Rao. 1987b. Assessment of drought resistance in pearl millet [Pennisetum americanum (L.) Leeke]: II. Estimation of genotype response to stress. Aust. J. Agric. Res. 38:49-59.

Bidinger, F.R., R. Serraj, S.M.H. Rizvi, C.J. Howarth, R.S. Yadav, and C.T. Hash. 2005. Field evaluation of drought tolerance QTL effects of phenotype and adaptation in pearl millet [Pennisetym glaucum (L.) R. Br.] topcross hybrids. Field Crops Res. 94:14-32.

Blum, A. 1988. Plant breeding for stress environments. CRC Press, Boca Raton, FL.

Eldin, M. 1993. Analyse de l'effect des deficits hydriques sur la recolte du mil au Niger, consequences agronomiques. p. 149160. In S. Hamon (ed.) Le mil en Afrique, diversity genetique et agro-physiologique: Potentialites et contraintes pour l'amelioriation et la culture. ORSTOM, Paris.

Fussell, L.K., F.R. Bidinger, and P. Bieler. 1991. Crop physiology and breeding for drought tolerance: Research and development. Field Crops Res. 27:183-199.

GENSTAT 6 Committee. 2002. GENSTAT 6 reference manual. Clarendon Press, Oxford, UK.

Lander, E., P. Green, J. Abrahamson, A. Barlow, M. Daly, S. Lincoln, and L. Newburg. 1987. MAPMAKER: An interactive computer package for constructing primary genetic linkage maps of experimental and natural populations. Genomics 1:174-181.

Li, Z.K., S.B. Yu, H.R. Lafitte, N. Huang, B. Courtois, S. Hittalmani, C.H.M. Vijayakumar, G.F. Liu, G.C. Wang, H.E. Shashidhar, J.Y. Zhuang, K.L. Zheng, V.P. Singh, J.S. Sidhu, S. Srivantaneeyakul, and G.S. Khush. 2003. QTL $\times$ environment interactions in rice: I. Heading date and plant height. Theor. Appl. Genet. 108:141-153. 
Liu, C.J., J.R. Witcombe, T.S. Pittaway, M. Nash, C.T. Hash, C.S. Busso, and M.D. Gale. 1994. An RFLP-based genetic linkage map of pearl millet (Pennisetum glaucum). Theor. Appl. Genet. 89:481-487.

Qi, X., S. Lindup, T.S. Pittaway, S. Allouis, M.D. Gale, and K.M. Devos. 2001. Development of simple sequence repeat markers from bacterial artificial chromosomes without subcloning. Biotechniques 31:355-362.

Qi, X., T.S. Pittaway, S. Lindup, H. Liu, E. Waterman, F.K. Padi, C.T. Hash, J. Zhu, M.D. Gale, and K.M. Devos. 2004. An integrated genetic map and a new set of simple sequence repeat markers for pearl millet, Pennisetum glaucum. Theor. Appl. Genet. 109:1485-1493.

Serraj, R., C.T. Hash, S.M.H. Rivzi, A. Sharma, R.S. Yaday, and F.R. Bidinger. 2005. Recent advances in marker-assisted selection for drought tolerance in pearl millet. Plant Prod. Sci. 8:334-337.

Singh, S.D., P. Singh, K.N. Rai, and D.J. Andrews. 1990. Registration of ICMA 841 and ICMB 841 pearl millet parental lines with A1 cytoplasmic-genetic male-sterility system. Crop Sci. 30:1378.

Utz, H.F., and A.E. Melchinger. 1996. PLABQTL: A program for composite interval mapping of QTL. Available at http:// wheat.pw.usda.gov/jag/papers96/paper196/indexp196.html (verified 15 Mar. 2007). J. Agric. Genomics 2:1.

Utz, H.F., A.E. Melchinger, and C.C. Schön. 2000. Bias and sampling error of the estimated proportion of genotypic variance explained by quantitative trait loci determined from experimental data in maize using cross validation and validation with independent samples. Genetics 154:1839-1849.

van Oosterom, E.J., F.R. Bidinger, V. Mahalakshmi, and K.P. Rao. 1996a. Effect of water availability pattern on yield of pearl millet in semi-arid tropical environments. Euphytica 89:163-174.

van Oosterom, E.J., V. Mahalakshmi, F.R. Bidinger, and K.P. Rao. 1996b. Effect of water availability and temperature on the genotype $\times$ environment interaction of pearl millet in semi-arid tropical environments. Euphytica 89:175-184.

van Oosterom, E.J., M.L. Whitaker, and E. Weltzien-Rattunde. 1996c. Integrating genotype $\times$ environment analysis, characterisation of drought patterns, and farmer preferences to identify adaptive plant traits for pearl millet. p. 383-402. In M. Cooper and G.L. Hammer (ed.) Plant adaptation and crop improvement. CAB Int., Wallingford, UK.

Veldboom, L.R., and M. Lee. 1996. Genetic mapping of quantitative trait loci in maize in stress and nonstress environments: I. Grain yield and yield components. Crop Sci. 36:1310-1319.

Witcombe, J.R., and C.T. Hash. 2000. Resistance gene deployment strategies in cereal hybrids using marker-assisted selection: Gene pyramiding, three-way hybrids, and synthetic parent populations. Euphytica 112:175-186.

Yadav, O.P., and E. Weltzien-Rattunde. 1999. Breeding for adaptation to abiotic stress. p. 317-336. In I.S. Khairwal et al. (ed.) Pearl millet breeding. Oxford and IBH, New Delhi, India.

Yadav, R.S., C.T. Hash, F.R. Bidinger, G.P. Cavan, and C.J. Howarth. 2002. Quantitative trait loci associated with traits determining grain and stover yield in pearl millet under terminal drought stress conditions. Theor. Appl. Genet. 104:67-83.

Yadav, R.S., C.T. Hash, F.R. Bidinger, K.M. Devos, and C.J. Howarth. 2004. Genomic regions associated with grain yield and aspects postflowering drought tolerance in pearl millet across stress environments and tester background. Euphytica 136:265-277. 